\title{
Using System Dynamics modelling approach to develop management tools for animal production with emphasis on small ruminants
}

\author{
L.O. Tedeschi , C.F. Nicholson , E. Rich
}

\begin{abstract}
A B S T R A C T
Small ruminants are important assets in several regions of the world. They account for more than half of the domesticated ruminants. Despite the growth in goat production in the world (more than $2 \%$ per year), research related to goat production is less than desired. One underused but potentially valuable approach for research on small ruminants is simulation modelling. Models of the components of small ruminant systems can enhance the financial returns and reduce negative environmental impacts. These models can be used to assess many dimensions of small ruminant production, from rumen dynamics to economic policies designed to support small ruminant production. Understanding the nutrition, production, and economic policy feedback signals and planning ahead is crucial to build a robust and integrated production activity that can be managed under different production scenarios. System Dynamics (SD) is a computer-aided modelling methodology that can be used to perform policy analysis and decision support system (DSS) applied to dynamic problems arising in complex social, managerial, economic, or ecological dynamic systems characterized by interdependence, mutual interaction, information feedback, and circular causality. SD can be used as a modelling tool to aggregate knowledge to solve different types of problems that have a limited scope to a specific location or have broad trends of applications across locations and areas of science. Important issues of broad application include the bearings of animal production in the climate change and the impacts of climate change in animal production, alternative production scenarios of animal and crop integration, associations between animal production and business (economics, marketing). The trend of increasing small ruminants in tropical and subtropical regions and an increasing pressure on tropical and subtropical livestock systems to produce food, to feed livestock, and to produce energy crops warrants the development of DSS to address issues such as what is the "real" benefits of livestock, the negative impacts livestock can have on greenhouse-gas emissions and the environment, and the effects of climate change on livestock systems.
\end{abstract}

\section{Introduction}

Sheep and goats are the most common domesticated small ruminant with worldwide economic impact
(Tedeschi et al., 2010a). Domestic sheep and goats were both domesticated more than 10,000 years ago in the Fertile Crescent region in the Zagros Mountains (Luikart et al., 2001). In the last 50 years, the population of small ruminants has increased from 1.35 billion in 1961 to 1.94 billion in 2006 and together they account for more than half of the domesticated ruminants (buffaloes, camels, cattle, goats, and sheep) (Haenlein, 1996). The number of goats has 
grown more than $2 \%$ per year, but sheep population has fluctuated without a clear pattern. Despite the growth in goat production in the US, research related to goat production is less than desired, which has limited genetic progress in milk or meat products, nutrition, and technology transfer (Sahlu et al., 2009). One underused but potentially valuable approach for research on small ruminants is simulation modelling. Models of the components of small ruminant systems have the potential to enhance the financial returns from small ruminant production and reduce negative environmental impacts such as excessive nutrient excretion. These models can be used to assess many dimensions of small ruminant production, from rumen dynamics to economic policies designed to support small ruminant production. Modelling provides a framework for the integration of scientific knowledge and allows for the creation of decision support systems (DSS) to make decisions regarding the improvement of animal production systems at a variety of levels (Tedeschi et al., 2010a).

The history of farm management was initially characterized by pragmatic, hands-on, on-farm research. In the beginning, agricultural economists applied theory-based analysis to develop rational planning and DSS for decision making processes (McCown and Parton, 2006). Even though several DSS have been developed to assist farm management, McCown and Parton (2006) indicated that model-based farm management was not developed to (or could not) assist practical farm managers at that time. Newman et al. (2000) indicated that even though DSS can assist producers in making better decisions by integrating information, limited adoption of DSS has persisted likely due to the lack of end user evaluation prior to and after the development of the tool and the complexity needed and/or the amount of input data is beyond the producers ability to operate the DSS.

Animal production systems (either at the level of the individual animal, the farm, or the market) are dynamically complex and it often can be difficult to manage in light of this complexity. The performance of each level is affected by previous decisions and by exogenous factors, and modelling can enhance decision-making through ex ante analyses of decision options and through monitoring and evaluation after decisions are implemented.

Understanding the nutrition, production, and economic policy feedback signals and planning ahead is crucial to build a robust and integrated production activity that can be managed under different production scenarios. In these situations, point estimate accuracy is less important than identifying trends and patterns that are robust under many conditions. Therefore, accurate and reliable knowledge management, including scientific knowledge, is an important step towards the success of any entrepreneurship's ability to make decisions that can affect the productivity and profitability of the activity. The coordination of production decisions with economic needs is a challenging task and can easily become the bottle neck of the entrepreneurship's operation scheme. Production indexes are frequently affected by management decisions, which in turn impact the revenue, consequently the profitability (Vieira et al., 2009).
A long-term successful entrepreneurship can be obtained by applying scientific knowledge management techniques to comprehend consequences, intended and unintended, of certain decisions before they are made. Because of the inherent complexity of agricultural activities and high risks associated with the product marketing and management of such activities, computer modelling becomes a valuable ally in addressing specific problems. Modelling is a powerful tool to help the user understand the likely implications (e.g. financial, environmental, and social) of diverse potential modifications to current production systems at the level of the animal subsystem, the animal, the farm, and the market. Ex ante impact assessment is valuable when the only alternative is trial and error, when experiments are costly or ethically unfeasible to assess the likely outcomes, or when a bad decision is likely to have significant negative effects (Sterman, 2000).

The objectives of this paper are (1) to describe the elements of one subset of dynamic simulation modelling methodology, (2) to illustrate previous and potential applications to small ruminant production systems at alternative scales (animal subsystem, animal, farm, and market/policy), and (3) to highlight how this modelling methodology can be used in future research topics related to small ruminant production systems to enhanced financial, environmental, and social outcomes.

\section{Modelling as a management tool}

Warren (2008) listed three important and distinct questions related to the success of a business through time as (a) why the historical performance behaved as it did? (b) where will the future performance take the entrepreneurship if continued as it was? and (c) how the future performance can be manipulated for improvement? Warren (2006) argues that System Dynamics (SD) can improve strategic management by applying four fundamental principles: performance over time, resources drive performance, flows of resource, and quantity of resources affect the retention and building of resources. Therefore, combining accumulated scientific information with knowledge and strategic management could improve agriculture and animal industry businesses around the world by better assessing marketing opportunities with biological limitations and potentials of the agroindustry.

\subsection{Systems Thinking and System Dynamics}

Systems Thinking (ST) and SD are two related but different paradigms. Systems Thinking is the recognition that organizations (and the world, for that matter) may be seen as a complex, integrated system in which a change made at a given time will ripple through the system and will impact other variables instantaneously or over time because they are connected in some way. Whereas SD is a methodology that applies ST in developing formal models that are used to describe (and simulate) the relationships among variables, including time, by clearly identifying the behaviour of the variables.

Systems Thinking is usually conceptual and its use does not lead to dynamic simulation analysis to understand 
behaviour; SD emphasizes the design of policies for guiding decisions. Forrester (2007) alerts that "the danger comes from encouraging people to believe that ST is the whole story. Systems Thinking is a sensitizer; it calls attention to the existence of systems. Some people feel they have learned a lot from the Systems Thinking phase. But they have gone perhaps only $5 \%$ of the way into understanding systems. The other 95\% lies in the SD structuring of models and simulations based on those models." In essence, Systems Thinking can be a door opener to SD, the first step towards understanding the dynamic complexity of problems.

Vennix (1996) suggested specific types of problems for which SD modelling is appropriate including (1) a dynamically complex problem (one for which the dynamics are important and for which unintended responses or outcomes are likely); (2) a recurring or persistent problem, perhaps one that has been unsuccessfully addressed in the past; (3) a problem for which is it possible to generate a "reference mode" behaviour over time that describes the inter-temporal nature of the problem; and (4) a problem involving a system that lends itself to thinking in stock and flow processes. Lyneis and Ford (2007) concluded that one of the most recognized use of SD has been project management such as modelling specific characteristics found in actual systems (processes, resources, managerial mental models, and decision making), controlling dynamics systems by modelling, analysing, and improving the system, and policy resistance and unintended consequences for adverse behaviours.

\subsection{System Dynamics modelling}

The diverse definitions of "systems" can be confusing. We adopted the definition of Meadows and Robinson $(1985,2002)$ that a system is something like "any set of interrelated elements." In a simple sense, a system can therefore be defined by its elements and the relationships among them. Systems can be analyzed with models, which are defined as "any set of generalizations or assumptions about the world" (Meadows and Robinson, 1985, 2002). Models can either be mental models (created and held within the mind of the analyst) or mathematical models which make explicit the model assumptions in mathematical form. In research settings, these models can be complementary, as the mental model provides the basis for the mathematical one, which when developed and used can stimulate revisions or expansions of the mental model. Many alternative mathematical approaches are possible to express the assumed relationships among the elements of the system, and each has strengths and limitations.

The SD modelling is a particular subset of dynamic simulation modelling. As with any method or approach, multiple definitions of SD exist. Sterman (2000; page 4) defines it as "a method to enhance learning in complex systems. . . fundamentally interdisciplinary. . . grounded in theory of nonlinear dynamics and feedback control developed in mathematics, physics, and engineering. .. to solve real-world problems." Thus, SD provides a set of conceptual tools to understand the structure and dynamics of complex systems. It also encompasses a modelling method that facilitates the development of formal computer simulations of complex systems and their use to design more effective technologies and policies. A key element is the emphasis on inter-temporal change: "System Dynamics deals with how things change through time, which includes most of what most people find important" (Richardson, 1991). Richardson (2001) further characterizes SD as "a computer-aided approach to policy analysis and design" that is applied "to dynamic problems arising in complex social, managerial, economic, or ecological systems", meaning "any dynamic systems characterized by interdependence, mutual interaction, information feedback, and circular causality."

A SD model is typically formulated as systems of ordinary differential equations that because of their complexity (and sometimes nonlinearity) are typically solved by numerical integration rather than by analytical methods. Because many disciplines have employed systems of differential equations in their analyses, this often leads to the observation that SD is "nothing new." In a mathematical sense, this is certainly true. However, it is worth noting that many mathematics and engineering texts and analyses emphasize analytical solutions to these systems (which often require linearization to be tractable) rather than numerical integration techniques, which allow a broader range of dynamic systems to be simulated - albeit with some inherent calculation error (integration error) as a result of the numerical integration techniques. It is also true that numerical integration techniques can be carried out using a variety of computer packages, including spreadsheets, and therefore no specialized software is required. But most SD practitioners would argue that the method is more than the application of certain mathematical methods. Rather, it involves the application of certain mathematical techniques with a particular perspective on the modelling process and interpretation of modelling outputs.

\subsubsection{The System Dynamics modelling perspective}

Focus on dynamic complexity. A central tenet of SD modelling is that dynamic systems are often complex and their behaviour usually cannot be understood well without formal simulation modelling (although conceptual modelling can still be useful). Moreover, there is a distinction made between "dynamic complexity" and "detail complexity." Detail complexity relates to the number of components in a system or the number of combinations one must consider in making a decision whereas dynamic complexity arises when the same action has dramatically different effects in the short run and the long run. In addition, dynamically complex systems frequently exhibit policy resistance, where the system acts over time to counter policies intended to improve the behaviour of the system.

Policy resistance. A long time known side effect of decision making process is trying to solve a problem and making it worse. This counterintuitive, unexpected dynamics often lead to policy resistance. Policy resistance arises because of an incomplete understanding of the full range of feedbacks within a system or because our system boundaries is not inclusive of important feedbacks or variables. 
Endogenous perspective. Another basic idea is that behaviours of a system arise not from external exogenous shocks, but from the structure of the system itself. According to Meadows and Robinson (1985), "The persistent dynamic tendencies of any complex system arise from its internal causal structure - from the pattern of physical constraints and social goals, rewards, and pressures that cause people to behave the way they do and to generate cumulatively the dominant dynamic tendencies of the total system. A system dynamicist is likely to look for explanations of recurring long-term social problems within this internal structure rather than in external disturbances, small maladjustments, or random events."

Emphasis on feedbacks. A central concept is the idea of two-way causation or feedback. Elements of a system can be related to each other through closed chains of causal relationships. Each such chain forms a feedback loop, and SD models are made up of many such loops linked together. Two kinds of feedback loops exist: positive loops tend to amplify any disturbance and to produce exponential growth, whereas negative loops tend to counteract any disturbance and to move the system towards an equilibrium point or goal. A model comprising several feedback loops linked non-linearly can produce a wide variety of complex behaviour patterns.

Explicit characterization of system stocks and flows. SD models usually make quite explicit the nature of variables included in the model. Typically, these can be characterized as stocks (states or levels), flows (rates), or auxiliary variables. These different types of variables are necessary because feedback processes usually do not operate instantly (Meadows and Robinson, 1985). System behaviour depends on the presence of system elements that can create inertia or delays.

Problem focus, not system focus. SD models typically focus on developing what is termed a dynamic hypothesis about the origins of a particular problematic behaviour (more on the process of SD modelling below). Thus, the focus is not typically on modelling all the relevant elements of a system that could be important, but only those elements that are necessary to explain a particular phenomenon. As with other modelling approaches, the problem focus provides a criterion by which to exclude or include model elements depending on whether they are necessary to replicate the observed behaviour.

Analysis of general dynamic tendencies. SD models are not primarily concerned with forecasting specific values of system variables at specific times. They are more interested in general dynamic tendencies; under what conditions the system as a whole is stable or unstable, oscillating, growing, declining, self-correcting, or in equilibrium. Moreover, SD places a high value on understanding the pattern of adjustment over time in response to various policy or technological interventions.

Broader variable and data definitions. In part as a result of the above, SD modellers tend to be willing to incorporate variables for which no explicit data are available, either for quantities that could in principle be quantified and collected, or for more conceptual variables. Sterman (2000) has noted that in addition to quantitative data, there is often a wealth of information useful for model develop- ment in unpublished records and the personal experiences of decision makers in the system. This has led to the development of formal group model-building techniques (i.e., participatory model development exercises) that have as a goal the development of appropriate model structures, but also integration of decision makers into the modelling process to strengthen model face validity and actual use (Vennix, 1996, 1999).

Use of archetypal structures. As discussed below, certain combinations of feedback loops recur frequently and allow system dynamicists to formulate a number of useful generalizations or theorems relating the structure of a system to the system's dynamic behavioural tendencies (Meadows and Robinson, 1985). Thus, a system dynamicist could view the impact of birth and death rates on an animal population as qualitatively similar to the impact of investment and depreciation on the aggregate capital stock of a national economy.

Model development and evaluation. The SD modelling process is explicitly iterative and self-critical. The process begins with the depiction of the problem through the behaviour of indicated variables over time. A causal model that links the variables into feedback structures is proposed and simulated. The model is parameterized to reproduce known behaviours. New policies that attempt to alter the problematic behaviour may be simulated through parametric change or the additional of new structures. Careful modellers examine the results at each stage of modelling to ensure consistent depiction of the problem and confidence in the solution (Barlas, 1989). Domain knowledge, critical to understanding the structure of problems, is often obtained through interviews, review of documentary materials, or through group model building, a technique where domain experts are led through a series of exercises that help them explicate their own mental models and come to consensus on problem structure (Andersen et al., 2007). Further discussion on adequacy of models was provided by Tedeschi (2006).

\subsubsection{Elements of $S D$ modelling}

Structure determines behaviour. SD models rest on the principle that system behaviour is determined by causal structure rather than specific events. Variables in these models are linked so that an increase in one causes an increase in another, or that an increase in one causes a decrease in another. These links combine to form feedback loops, where variable $A$ may influence variable $B$, which in turn influences variable $A$ at a later point. As discussed above, loops are either termed reinforcing (positive) or balancing (negative) depending on the aggregate polarity of each link. These loops support the perspective of SD that problems are best understood when their endogenous nature is made explicit, and circular causality made explicit.

Stocks, flows, and information delays. SD models distinguish between stocks and flows within causal structures. Stocks are accumulations over time, and flows increase or decrease them. The classic example of a stock is a bathtub (e.g. Sweeney and Sterman, 2000), where the level of water is determined by the difference between the inflow of the water tap and the outflow of the drain. Information 

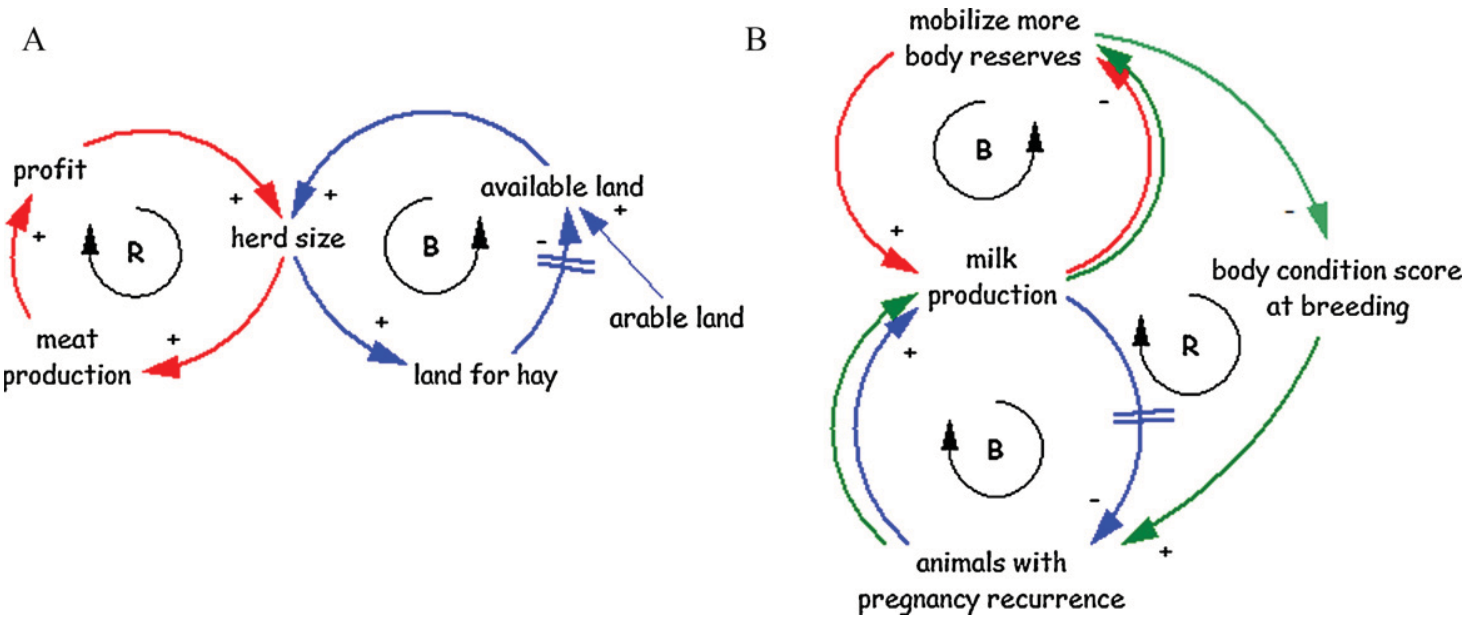

Fig. 1. Examples of: (A) limit to growth and (B) shifting the burden archetypes.

about the relative level of water in the tub can be used to create a feedback mechanism that changes the inflow once capacity is reached. If there is a delay of information about the level of water to the mechanism, however, the bathtub may overflow before action is taken.

Causal modelling and formal simulation. Although insight from the specification of causal loops underlying a system provides insight, additional value comes from the formal specification and simulation of these structures. SD models may be represented as a series of coupled first-order differential equations, a set of parameters and a vector of non-linear functions. Numerical simulation of the system forces algebraic rigour upon the model and supports the examination of the effects of parametric and structural change on the system. Changes in model assumptions may be observed through their effect on behaviour over time. Several simulation packages are available to support experimentation and analysis.

Building blocks of behaviour. The combination of loops, stocks, flows and delays produce a few distinct patterns of behaviour with known structures that form the basis of larger SD models. The most fundamental modes of behaviour are exponential growth, goal seeking, and oscillation. Other modes are S-shaped growth, S-shaped growth with overshoot and oscillation, and overshot and collapse that originates from combinations of the fundamental modes (Sterman, 2000).

\subsubsection{Archetypes}

Archetypes are more complex structures (combination of stocks and flows) derived from the fundamental structures that occur over and over again in different fields of the science. They embody the essence of modelling complexity using known patterns and structures. The ability to identify these archetypes allows one to quickly see more and more places where there is leverage to solve difficult challenges and to find solutions to diverse types of problems, but yet having a common structure behind them. The two most common ones are limits to growth and shifting the burden (Fig. 1); other archetypes were presented by Senge (1990).
Limits to growth. It is comprised of two feedback looks: a reinforcing loop that generates results and a balancing loop that slows down the results typically driven by a limiting condition (Senge, 1990). The common situation is an initial increase of animal product due to adoption of technology and better genetic animals, but later on the production is limited by available arable land to produce more need feed to support the increase in the animal science when at the limit of production, an unforeseen problem occur with the feed production, animal number will have to decrease.

Shifting the burden. A problem requires a solution, but the needed solution uses more resource or time. An alternative, cheap solution is used instead. Unfortunately, the quick, cheap solution does not take care of the problem, only the symptoms; the problem grows worse (Senge, 1990). This archetype has two balancing loops (correct and temporary solutions) and a reinforcing loop (sideeffect). A typical example is the milking production and reproduction indexes in dairying animals. The average milk productivity of a dairy farm is declining. The fundamental solution is to better balance nutrition with the available animal and feed resources (Tedeschi et al., 2010b); but it takes time and commitment. The quick, cheap solution is to increase the number of more "efficient" animals. These more "efficient" animals may mobilize more body reserves in support of lactation and consequently pregnancy will be more difficult. The reproduction indexes start falling and the average milk productivity declines even more. Another quick solution is to sell the lactating cows at younger ages ( 2 or 3 calving cycles). The long run problem in this case is the problems associated with calving and not being able to retain efficient cows.

\section{Agribusiness modelling}

Because SD modelling is flexible and it has an intuitive development environment, it is suitable for modelling "big picture"-type problems. One limitation that has limited the adoption of DSS is the lack of tighter relationships among the parties involved in the problem during the model development, evaluation, and redesign phases. The 


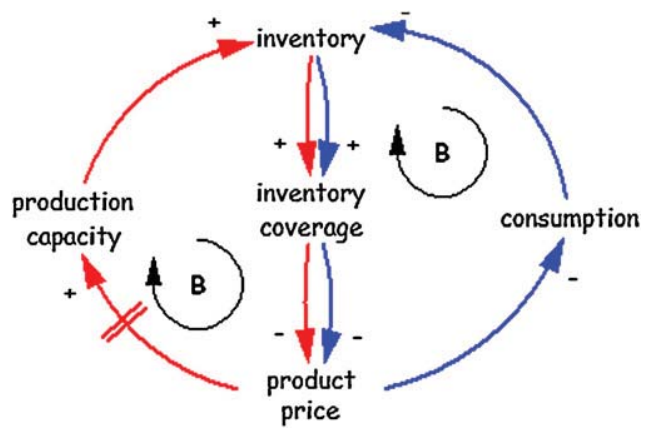

Fig. 2. A causal loop diagram of the general feedback structure of production cycles.

communication between the expert, the developer (modeller), and the end user has to be open (frank) and dynamic. The SD approach supports this "feedback" interaction and allows for group model-building practices in which the client (i.e., end user) is deeply involved in the modelling processes (Vennix, 1999).

There are several ways to build a model. Formal methodology of modelling practices involve the learning of known mathematical relationships of biological responses, metabolism pathways, enzyme kinetics, econometric data, regressions [e.g. Baldwin (1995), Haefner (1996), Thornley and France (2007)]. The SD approach relies on simple (few variables) and complex (archetypes) structures that create the observed (or perceived) behaviour over time or between variables [e.g. Sterman (2000)]. There has been a rather small number of animal agriculture models based on the SD approach since the foundation of the SD in the late 1950s compared to other fields of science such as business (Lyneis, 2000; Sterman, 2000) and environment (Anand et al., 2006; Fiddaman, 2007; Ford, 1999).

It is most likely the first animal production model based on the SD approach was devised by Meadows (1970). A SD model to understand the general dynamics of commodity production cycles was presented for the hog, chicken, and cattle industries. The purpose of the model was to devise stabilization policies of these animal production activities. Fig. 2 depicts two balancing (negative) feedback loops (i.e., consumption and production) impacting the inventory and product price that are the basic structure of the commodity production cycles as proposed by Meadows (1970). His model included empirical relationship between inventories and prices, and common characteristics of biological, physical, and psychological delays. The simulations of the model was able to mimic the observed cyclic/oscillatory behaviour for the hog (4 years), chicken (30 months), and cattle (15 years) productions. Based on these simulations, Meadows (1970) concluded that available statistical data and the proposed model structure were able to explain the periodicity and the stability of the commodity cycles studied.

A more detailed SD model of the cattle and corn production cycles was presented by Conrad (2004). His model was based on that developed by Meadows (1970), but the objective was to understand the propagation of effects of large-scale disruptive events (i.e., disease, malevolent attack). The results of his model simulations indicated that relative low cost preventive measures to protect the cow/calf operations could decrease the oscillatory behaviour (dampen) of beef price, beef sales, and beef cattle population in general.

Recently, Guimarães et al. (2009) developed a SD model to understand how some biological aspects would impact the herd dynamics of dairy goats under a Brazilian production scenario. Besides the typical gestating, lactating, breeding animal stocks commonly assumed by the models based on Meadows (1970) work, Guimarães et al. (2009) added a second dimension of aging chain complexity by creating up to five parturition stages. The gestating, lactating, and breeding dynamics were modelled within each parturition component as shown in Fig. 2 of Guimarães et al. (2009) work. Their work confirmed that reproductive and sanitary aspects of the dairy goat industry are crucial to ensure successful long life entrepreneurship. In addition, they suggested that two breeding season is more profitable with a greater turnover than the one breeding season under the conditions they investigated. Future work should combine their model within the scope of the dynamics suggested by Meadows (1970) as shown in Fig. 2 to model the macroeconomic impact on dairy goat production.

Parsons et al. (2010b) developed in integrated croplivestock model to study the sheep farming systems of the Yucatán peninsula, Mexico. They used principles of SD to build a stock-flow feedback model to aggregate nutrition, production, and manure management information from the Small Ruminant Nutrition System [SRNS; (Tedeschi et al., 2010a)] with weather, crop, and soil dynamic data from the Agricultural Production Systems Simulator [APSIM; (Keating et al., 2003)]. They simulated scenarios that contrasted specialized systems versus mixed farming. Parsons et al. (2010a) concluded that mixed enterprise scenarios involving sheep provided more income than specialized enterprises, and capitalized on a lower price of on-farm maize grain, efficient utilization of surplus labour, and availability of common land. The profitability was greater for producers when they sold excess grain and maize stover and used common land to feed the livestock. Their analysis suggested that increased integration does not always result in improved outcomes.

\subsection{A case study of market and policy application to small ruminant systems}

In recent years, there has been a great deal of discussion about the potential of sheep production as a "development opportunity" for the region of south eastern Mexico. The market for sheep meat has been growing in Mexico City and an increasing number of producers in the Yucatán and elsewhere have begun sheep production, either switching from other agricultural activities or adding sheep production to their mix of activities. Surveys conducted in June-August 2004 indicate that sheep producers generally fall into one of two categories: "commercial" producers, who are larger and make more use of production technologies and information, and traspatio producers who operate on a smaller scale and make less use of productivity-enhancing technologies. In response to the perceived opportunity for 
sheep production to contribute to the region's economic growth, the state government of Yucatán has granted subsidies to sheep producers, particularly in the form of subsidized loans or outright cost-sharing grants, often to larger producers. This has lowered the investment cost for entry into larger-scale sheep production. Subsidies are offered to smaller-scale producers as well, but the amounts tend to be smaller. At the same time, researchers at a number of Gulf region Universities and the national agricultural research service (INIFAP) have been working on technologies and practices to improve the productivity of the systems (e.g. reduce mortality, increase feed production and quality).

Little is known to date about the characteristics of demand growth in Mexico City (i.e., the growth rate), or basic economic parameters (price and income elasticity). Most policy makers seem to be operating under the assumption that the current rate of demand growth will continue indefinitely, and that sheep meat prices will remain at levels profitable for producers regardless of the actions that producers take in response to the current levels of profitability. Particularly given the delays in responding to increased incentives for sheep production, and the possibility that producers (and policy makers) in one region have limited knowledge about the decisions of producers (and policy makers) in other regions, there seems to be the potential for cyclical behaviour in sheep prices at a minimum and "overshoot and collapse" behaviour at worst in the Yucatán sheep sector. The purpose of the model developed by Nicholson and Parsons (personal communication) was to explore the impacts of various demand growth patterns, technological change, and policies (e.g. investment subsidies) on the profitability of Yucatecan sheep production.

Their model included two regions (Yucatán and "Other") and two (aggregated) types of producers ("adopters" and "non-adopters"). The adopters are those producers who will use a technology when it is introduced, and therefore will see direct changes in their production systems as a result. The proportion of the adopters who use a technology is assumed to demonstrate sigmoidal growth over time. The model included a single aggregated "local" feed resource, which assumes that most of the feed resources used in sheep production are forage or browse and are available locally (i.e., not traded among regions or producers). Feed production depends on the land area, feed produced per land area and relative (regional) rainfall. Feed consumption depends on the number of animals, their per-month consumption, and the availability of feed per animal. A single aggregated sheep market (i.e., in Mexico City) consists of an inventory of sheep meat (i.e., distinct from sheep numbers) and feedback loops that adjust the sheep meat price and sales. Although income and population growth will be the key drivers of sheep meat demand, the model does not include these directly. Rather, their model included structure to create exogenous linear growth in demand to test the impact of various growth patterns on the sheep production and marketing system. The sheep meat price was assumed to translate into a producer sheep price by subtracting the per $\mathrm{kg}$ meat marketing costs (assumed to be $50 \%$ of the meat price) and multiplying by the amount of meat per animal ("carcass yield"). Meat marketing costs were assumed to vary by region and producer type (to reflect the potential relative disadvantage to Yucatecan producers and smaller "non-adopter" producers). This implies that the net price received by producers, and the aggregated net margin, will differ by region and producer type. Producer revenues are calculated as animal sales time animal prices. Producer costs include fixed and variable costs. Nicholson and Parsons' (unpublished) modelling framework was used to assess the impact of two factors: (1) a technology to increase feed production in Yucatán that is used only by "adopter" sheep farmers, and (2) a constant $0.5 \%$ growth in demand for sheep meat throughout the simulation.

Increased feed productivity. The effect of this technology is to increase feed production, increase feed availability per animal, and nearly two years after the technology is introduced, increase the number of young sheep sold by Yucatecan adopters. This policy had the effect of reducing the animal prices for all producers. Adopting producers increase revenues and net margin because they increase their flocks of breeding sheep numbers and are selling more young stock. Net margin for other producers was decreased and was sometimes negative for Yucatecan non-adopters. Net margin oscillates for all producers given the delays in the feedback structure. Thus, increasing feed availability has the impact of increases net margin for some farmers and reducing it for others through increases in the supply of sheep meat and lower prices.

Constant demand growth. Under this scenario, there was an initial increase in the sheep meat price that resulted from a reduction in the number of young stock sold because producers initially withhold these from the market to increase the size of their breeding flocks. This is analogous to the well-known phenomenon in Meadows (1970) hog model and "cattle cycles" (Mundlak and Huang, 1996) where an increase in price actually decreases the supply available in the short run. Despite an ever-growing demand, producer net margin does not continue to grow. There is "overshoot" behaviour in both meat prices and net margins, with the result that producer incomes are declining from their peak after a few highly profitable years. This indicates that there are likely to be near-term limits to the development opportunities for increased sheep production, even if demand continues to increase indefinitely.

\section{Developing agribusiness models for the tropical and subtropical regions}

The special ability of ruminant animals in converting non-competitive feed sources (e.g. cellulose) to food and other products that are useful to human is incontestable (Fitzhugh, 1978), but its real benefits and long-term feasibility have been challenged lately.

A major contemporary issue impacting agriculture worldwide is the climate change. The human population growth, urban sprawl, and increased incomes vastly increase the consumption of animal products, particularly in developing countries (Bradford, 1999; Delgado et al., 1999). In addition to the climate change (either by anthropological or natural reasons), the transition of 
relatively extensive, low input/output livestock systems to intensified, high input/output scheme of production (industrialization) have several adverse environmental impacts, such as deterioration of pasture due to overgrazing, scarcity of surface and groundwater supplies, gaseous emissions and air quality, pollution of land and water with animal wastes (Powell et al., 1999). Agriculture impacts the climate (e.g. deforestation, fertilization, over-usage of water and soil, intensification of animal production) and the climate (temperature, sunlight, rainfall) affects the agriculture in several ways (Nelson et al., 2009). Even though, within a given context, some agriculture production can benefit from [a level of] "global warming" (Topp and Doyle, 1996a,b), the sum of drawbacks may offset these specific benefits in a general sense. Part of this not-so-sure impact of "global warming" in agriculture and more specifically livestock systems stems from the fact that "little is known about the interactions of climate and increasing climate variability in livestock systems" (Thornton et al., 2009) from a biological perspective and even less is known from an economical and marketing points of view.

Therefore, the development of "big picture" models to understand the key variables and their feedback loops that can impair agriculture, specifically animal production, is essential to devise corrective and preventive policies to prevent shortage of animal products (i.e., meat, milk) and avoid chaotic behaviour in the international supply chain. Rivington et al. (2007) concluded that an integrated assessment approach (e.g. System Thinking and System Dynamics) in which simulation modelling are developed in conjunction with decision makers and stakeholders can generate credible and relevant assessments of climate change impacts on farming systems. They argued that simulation modelling can be used to exploit different ways climate change can be affected while testing for corrective measures and their effective attenuation of the problems.

As with any other region in the world, animal feeding and feeds are the major source of the production costs of animal production (Gonçalves et al., 2008). Therefore, supplied amount of feed, which is a function of energy concentration of the diet and animal production, and feed cost have to be taken into account when developing animal models if sustainability of the production is sought for a given region. Another important aspect is reproduction because it is directly connected to the ability of a farmer to expand its production (either by retaining more animals or obtaining new animal genetics) and consequently increase profitability by taking advantage of the economy of scale. Guimarães et al. (2009) has indicated that pregnancy and mortality rates are the main variables affecting the expansion of dairy goat herds.

Understanding the interplay between aggregate demand for animal products, production factors, demand, and their relationships to the environment is crucial to government policy and industrial activity. The controversial book Limits to Growth by Meadows et al. (1972) presented a model of world population and food dynamics. Through the application of multiple hypotheses representing the timing and level of population growth, productivity changes, and demand for food, they demonstrated that there were plausible scenarios where the demand for food and production overshoots its ability to provide them, leading to long-term, irreversible economic decline. While the more sensational doomsday scenarios captured the attention of the media and scholars, other scenarios identified how changes in population policy and consumption of resources in the short term could create a sustainable future. In the revisited model (Meadows et al., 2004), authors asserted that some of the sustainable policies identified in the earlier work are no longer viable. The reinforcing loops driving population growth have driven resource demand (water, energy reserves) past their ability to rebuild spontaneously, causing them to degrade in supply and quality.

Athough there continues to be debate about the conclusions of Meadows et al. (1972) work, the true value of this (and any) model is its ability to capture and focus discussion on the market processes and assumptions that drive the outcomes. System Dynamics models work at very abstract levels that focus on problem structure rather than on forecasting from large data sets. The parsimonious use of data is an important feature of the SD process, as it permits analysis in situations where data is uncertain or simply not available. If analysis of a few key variables demonstrates important differences to the problem and outcomes, then those variables can become the objective for targeted data collection.

System Dynamics can be used as a modelling tool to aggregate knowledge to solve different types of problems that have a limited scope to a specific location or have broad trends of applications across locations and areas of science. Its robust methodology and rigorous mathematical background allows the identification of key variables affecting the outcome and the model development in a collaborative environment. Important issues of broad application affecting animal production include climate change ("global warming"), alternative production scenarios of animal and crop integration, association between agriculture (more specifically animal production) and business (economics, marketing).

The trend of increasing small ruminants in tropical and subtropical regions and an increasing pressure on tropical and subtropical livestock systems to produce food, to feed livestock, and to produce energy crops warrants the development of DSS to address issues such as what is the "real" benefits of livestock, the negative impacts livestock can have on greenhouse-gas emissions and the environment, and the effects of climate change on livestock systems.

\section{Conflict of interest}

None of the authors listed above has a financial or personal relationship with other people or organisations that could inappropriately influence or bias the paper entitled "Using System Dynamics modelling approach to develop management tools for animal production with emphasis on small ruminants."

\section{References}

Anand, S., Vrat, P., Dehiya, R.P., 2006. Application of a system dynamics approach for assessment and mitigation of $\mathrm{CO}_{2}$ emissions from 
the cement industry. Journal of Environmental Management (79), 383-398.

Andersen, D.F., Vennix, J.A.M., Richardson, G.P., Rouwette, E.A.J.A., 2007. Group model building: problem structing, policy simulation and decision support. The Journal of the Operational Research Society (58), 691-694.

Baldwin, R.L., 1995. Modeling Ruminant Digestion and Metabolism. Chapman \& Hall, New York, p. 578

Barlas, Y., 1989. Multiple tests for validation of system dynamics type of simulation models. European Journal of Operational Research (42), 59-87.

Bradford, E., 1999. Animal Agriculture and Global Food Supply. Council for Agricultural Science and Technology.

Conrad, S.H., 2004. The dynamics of agricultural commodities and their responses to disruptions of considerable magnitude. In: Proceedings of the International Conference of the System Dynamics Society, 22 , Oxford, England, p. 13.

Delgado, C., Rosegrant, M., Steinfeld, H., Ehui, S., Courbois, C., 1999. Livestock to 2020: The Next Food Revolution. International Food Policy Research Institute.

Fiddaman, T., 2007. Dynamics of climate policy. System Dynamics Review (23), 21-34.

Fitzhugh, H.A., 1978. Bioeconomic analysis of ruminant production systems. Journal of Animal Science (46), 797-806.

Ford, A., 1999. Modeling the Environment: An Introduction to System Dynamics Modeling of Environmental Systems. Island Press, Washington, DC, p. 401.

Forrester, J.W., 2007. System dynamics-a personal view of the first fifty years. System Dynamics Review (23), 345-358.

Gonçalves, A.L., Lana, R.P., Vieira, R.A.M., Henrique, D.S., Mancio, A.B., Pereira, J.C., 2008. Evaluation of systems of production of dairy goats in the region Southeast of Brazil. Revista Brasileira de Zootecnia (37), 366-376.

Guimarães, V.P., Tedeschi, L.O., Rodrigues, M.T., 2009. Development of a mathematical model to study the impacts of production and management policies on the herd dynamics and profitability of dairy goats. Agricultural Systems (101), 186-196.

Haefner, J.W., 1996. Modeling Biological Systems: Principles and Applications, 1st ed. Chapman \& Hall, New York, p. 473.

Haenlein, G.F.W., 1996. Status and prospects of the dairy goat industry in the United States. Journal of Animal Science (74), 1173-1181.

Keating, B.A., Carberry, P.S., Hammer, G.L., Probert, M.E., Robertson, M.J., Holzworth, D., Huth, N.I., Hargreaves, J.N.G., Meinke, H., Hochman, Z., McLean, G., Verburg, K., Snow, V., Dimes, J.P., Silburn, M., Wang, E., Brown, S., Bristow, K.L., Asseng, S., Chapman, S., McCown, R.L., Freebairn, D.M., Smith, C.J., 2003. An overview of APSIM, a model designed for farming systems simulation. European Journal of Agronomy (18), 267-288.

Luikart, G., Gielly, L., Excoffier, L., Vigne, J.-D., Bouvet, J., Taberlet, P., 2001. Multiple maternal origins and weak plylogeographic structure in domestic goats. Proceedings of the National Academy of Science of the United States of America (98), 5927-5932.

Lyneis, J.M., 2000. System dynamics for market forecasting and structural analysis. System Dynamics Review (16), 3-25.

Lyneis, J.M., Ford, D.N., 2007. System dynamics applied to project management: a survey, assessment, and directions for future research. System Dynamics Review (23), 157-189.

McCown, R.L., Parton, K.A., 2006. Learning from the historical failure of farm management models to aid management practice. Part 1 . The rise and demise of theoretical models of farm economics. Australian Journal of Agricultural Research (57), 143-156.

Meadows, D.H., Meadows, D.L., Randers, J., Behrens III, W.W., 1972. The Limits to Growth: A report for the Club of Rome's Project on the Predicament of Mankind. Universe Books, p. 205.

Meadows, D.H., Randers, J., Meadows, D.L., 2004. The Limits to Growth: The 30-year Update. Chelsea Green Publishing Company, p. 338.

Meadows, D.H., Robinson, J.M., 1985. The Electronic Oracle: Computer Models and Social Decisions. John Wiley and Sons, New York, p. 445.

Meadows, D.H., Robinson, J.M., 2002. The electronic oracle: computer models and social decisions. System Dynamics Review (18), 271-308.

Meadows, D.L., 1970. Dynamics of Commodity Production Cycles. WrightAllen Press, Cambridge, MA, p. 104.

Mundlak, Y., Huang, H., 1996. International comparisons of cattle cycles. American Journal of Agricultural Economics (78), 855-868.

Nelson, G.C., Rosegrant, M.W., Koo, J., Robertson, R., Sulser, T., Zhu, T., Ringler, C., Msangi, S., Palazzo, A., Batka, M., Magalhaes, M., Valmonte-Santos, R., Ewing, M., Lee, D., 2009. Climate Change; Impact on Agriculture and Costs of Adaptation. International Food Policy Research Institute.
Newman, S., Lynch, T., Plummer, A.A., 2000. Success and failure of decision support systems: Learning as we go. In Proc. Am. Soc. Anim. Sci. Available at: http://www.asas.org/JAS/symposia/proceedings/0936.pdf. (accessed 09112006 ).

Parsons, D., Nicholson, C.F., Blake, R.W., Ketterings, Q.M., Ramírez-Avilés, L., Cherney, J.H., Fox, D.G., 2010a. Application of a simulation model for assessing integration of smallholder shifting cultivation and sheep production in Yucatán, Mexico. Agricultural Systems (104), 13-19.

Parsons, D., Nicholson, C.F., Blake, R.W., Ketterings, Q.M., Ramírez-Avilés, L., Fox, D.G., Tedeschi, L.O., Cherney, J.H., 2010b. Development and evaluation of an integrated simulation model for assessing smallholder crop-livestock production in Yucatán, Mexico. Agricultural Systems (104), 1-12.

Powell, J.M., Jackson-Smith, D., Van Bruchem, J., 1999. Environmental issues facing ruminant livestock production in mixed farming systems. In: Jung, H.-J. G., Fahey Jr., G.C. (Eds.), Proceedings of the 5th International Symposium on the Nutrition of Herbivores. American Society of Animal Science, San Antonio, TX, pp. 778-819.

Richardson, G.P., 1991. Feedback Throught in Social Science and Systems Theory. University of Pennsylvania Press, Philadelphia, PA, p. 374.

Richardson, G.P., 2001. System dynamics. In: Gass, S., Harris, C.M. (Eds.), Encyclopedia of Operations Research and Management Science. , 2nd ed. Kluwer Academic Publishers, Boston, pp. 807-810.

Rivington, M., Matthews, K.B., Bellocchi, G., Buchan, K., Stöckle, C.O., Donatelli, M., 2007. An integrated assessment approach to conduct analyses of climate change impacts on whole-farm systems. Environmental Modelling \& Software (22), 202-210.

Sahlu, T., Dawson, L.J., Gipson, T.A., Hart, S.P., Merkel, R.C., Puchala, R., Wang, Z., Zeng, S., Goetsch, A.L., 2009. ASAS Centennial Paper: impact of animal science research on United States goat production and predictions for the future. Journal of Animal Science (87), 400-418.

Senge, P.M., 1990. The Fifth Discipline: The Art and Practice of the Learning Organization. Currency Boubleday, New York, p. 423.

Sterman, J.D., 2000. Business Dynamics: Systems Thinking and Modeling for a Complex World. Irwin McGraw-Hill, New York, p. 982.

Sweeney, L.B., Sterman, J.D., 2000. Bathtub dynamics: initial results of a systems thinking inventory. System Dynamics Review (16), 249-286.

Tedeschi, L.O., 2006. Assessment of the adequacy of mathematical models. Agricultural Systems (89), 225-247.

Tedeschi, L.O., Cannas, A., Fox, D.G., 2010a. A nutrition mathematical model to account for dietary supply and requirements of energy and nutrients for domesticated small ruminants: the development and evaluation of the small ruminant nutrition system. Small Ruminant Research (89), 174-184.

Tedeschi, L.O., Fox, D.G., Roseler, D.K., 2010b. An interactive, mechanistic nutrition model to determine energy efficiency of lactating dairy cows. In: Sauvant, D. (Ed.) Modelling Nutrient Digestion and Utilization in Farm Animals, 7th, University of Wageningen Press, Paris, France, pp. 252-262.

Thornley, J.H.M., France, J., 2007. Mathematical Models in Agriculture, 2nd ed. CABI Publishing, Wallingford, UK.

Thornton, P.K., van de Steeg, J., Notenbaert, A., Herrero, M., 2009. The impacts of climate change on livestock and livestock systems in developing countries: a review of what we know and what we need to know. Agricultural Systems (101), 113-127.

Topp, C.F.E., Doyle, C.J., 1996a. Simulating the impact of global warming on milk and forage production in Scotland. 1. The effects on dry-matter yield of grass and grass-white clover swards. Agricultural Systems (52), 213-242.

Topp, C.F.E., Doyle, C.J., 1996b. Simulating the impact of global warming on milk and forage production in Scotland. 2. The effects on milk yields and grazing management of dairy herds. Agricultural Systems (52), 243-270.

Vennix, J.A.M., 1996. Group Model Building: Facilitating Team Leaning Using System Dynamics. John Wiley and Sons Ltd, Chichester, NY, p. 297.

Vennix, J.A.M., 1999. Group model-building: tackling messy problems. System Dynamics Review (15), 379-401.

Vieira, R.A.M., Cabral, A.J., de Souza, P.M., Fernandes, A.M., Henrique, D.S., Real, G.S.C.P.C., 2009. Dairy goat husbandry amogst the household agriculture: herd and economic indexes from a case study in Rio de Janeiro, Brazil. Revista Brasileira de Zootecnia (38), 204-213.

Warren, K., 2006. Improving strategic management with the fundamental principles of systems dynamics. System Dynamics Review (21), 329-350.

Warren, K., 2008. Strategic Management Dyanmics. John Wiley \& Sons, Ltd, West Sussex, England, p. 696. 